\title{
Prevalence of Otorhinolaryngological Symptoms in Covid 19 Patients
}

\author{
Saee Savtale $^{1}\left[\right.$ Prashant Hippargekar $^{1} \cdot$ Sudhir Bhise $^{1} \cdot$ Shankar Kothule $^{1}$
}

Received: 17 November 2020/ Accepted: 18 January 2021/Published online: 8 February 2021

(C) Association of Otolaryngologists of India 2021

\begin{abstract}
To determine prevelance of ENT symptoms in COVID 19 positive patients. A cross sectional study was performed at SRTR GMC AMBAJOGAI, a tertiary care hospital amongst the patients admitted in COVID 19 isolation ward with a positive RT-PCR report. Amongst the included 180 patients, 112 patients had one or more ENT related symptoms that included throat pain (47.2\%), loss of smell $(55.5 \%)$, loss of taste $(58.8 \%)$ and hearing loss (54.44\%) along with generalized COVID 19 symptoms. ENT symptoms can be considered as biomarkers for early diagnosis of Covid-19 patients ensuring faster treatment and isolation allowing better containment of the disease.
\end{abstract}

Keywords Otorhinolaryngological symptoms · Covid-19 . Loss of smell and taste $\cdot$ Symptomatology

\section{Introduction}

The Severe Acute Respiratory Syndrome Coronavirus 2 (SARS-CoV-2), firstly known as the 2019 novel Coronavirus, started in Wuhan in China at December 2019 [1]. Since that moment, the COVID-19, has cast its spell all over the world crossing all countries' borders till the World

Saee Savtale

myself.10395.ss@gmail.com

Prashant Hippargekar

pmhippargekar@gmail.com

Sudhir Bhise

bhisesudhir13@gmail.com

Shankar Kothule

kothule1986@gmail.com

1 Otolaryngology Department, SRTR GMC, Ambajogai, India
Health Organization (WHO) confirmed it as a pandemic disease on March 11, 2020 [2]. Several reports suggesting high rate of infectivity among health care workers were published. Working constantly on mucosal surfaces with high viral loads, it became apparent that Otorhinolaryngologists were at higher risk [3]. The COVID-19 initially presented mainly by lower respiratory tract related symptoms such as fever, cough, dyspnea and chest tightness that could progress rapidly to acute respiratory distress syndrome (ARDS) [4]. However, myriad of other symptoms were later documented indicating a multi systemic involvement of the disease. From being asymptomatic or having mild fever, cough, myalgia and chest pain to succumbing to respiratory failure or DIC, presentations of COVID 19 show a wide spectrum especially in India. In addition, ear, nose, and throat (ENT) symptoms, including loss of sense of smell and/or loss of sense of taste (STL) have been reported in several patients [5].

Considering the lack of published data on ENT manifestations in COVID 19 and the high susceptibility of an otolaryngologist to aerosol transmission and droplet infection during examination, the aim of the current work was to detect and discuss the different otorhinolaryngology (ORL) manifestations those were reported in COVID-19 positive patients $[1,6]$.

\section{Materials and Methods}

A cross sectional survey analysis on all patients admitted in the isolation ward of SRTR GMC, Ambajogai with a confirmed polymerase chain reaction (PCR)-positive testing for the SARS-CoV-2 viral genome in their nasopharyngeal and oropharyngeal swab, was conducted during the COVID-19 outbreak in India. In addition, many other 
patients and health workers (nurses, physicians, etc.) with confirmed positive PCR test results were voluntarily enrolled in the study. The study protocol was approved by the Ethics Committee. All subjects provided informed consent to participation in the study. Patients admitted in the hospital with a positive RT-PCR report between the duration of 1st October, 2020 and 15th October, 2020 were included in the study. The exclusion criteria were as follows: age $<18$ years old, failure to complete the whole questionnaire, symptoms present 2 months before the positive test result, no confirmed positive PCR test result, recent commencement of treatment with new drugs, a history of chronic nasal problems and recent head injury or brain and/or nose operations, severe respiratory failure, or in the intensive care unit.

\section{Survey Analysis}

A verbal survey was conducted among these patients who consented for the study. A detailed history was taken with regards to the presence of generalize COVID related symptoms and prevelance of otorhonolaryngological complaints in those patients. During the interviews, it was also made sure that Otorhinolaryngologic symptoms were of new onset and were not explained by any other underlying disease.

They were also asked about the onset time of the symptoms to assess symptom duration and time from onset to diagnosis.

Patients were then examined for any positive findings in ear nose throat as per routine ENT examination guidelines in consideration with COVID 19.

\section{Results}

A total of 185 patients answered all questions during the study period. 5 patients were excluded from the analysis2 had chronic STL due to chronic rhinosinusitis, 1 underwent septal surgery 1 week before the outbreak while 1 had persistent sore throat due to chronic steroid inhaler on account of asthma. Therefore, the final analysis was performed in 180 patients. The patients ranged in age from 18 to 65 years ( $37.8 \pm 12.5$ years), $66.6 \%$ were females, and $76.6 \%$ were nonsmokers.

The most obvious symptom at the time of presentation was noted and frequency was tabulated. The most obvious symptoms of patients at presentation were fever $(\mathrm{n}=171$, $95 \%)$, fatigue $(\mathrm{n}=168,93.33 \%)$, dyspnea $(\mathrm{n}=162,90 \%)$, cough $(\mathrm{n}=150,83.33 \%)$ as seen in Table 1 Denotes frequency of generalised COVID 19 symptoms.
Duration of each generalized symptom and duration between onset of symptom and time of hospital referral with recovery time was noted and shown in Table 2.

On detailed history taking, ENT symptoms with their frequency in the sample size and duration before the time of diagnosis were calculated and are depicted in Tables 3 and 4. The most common ENT symptoms were found to be loss of smell and taste sensations followed by hearing loss, tinnitus and throat pain.

Hyposmia/anosmia and aguesia were both sudden in onset and had a higher frequency in younger population. All these patients reported complete recovery $2.5 \pm 0.5$ days before hospital referral. Hearing loss was sudden in onset and was more prominent in older age group. $54.44 \%$ patients reported hearing loss after the diagnosis/hospital referral.81.6\% of these patients reported complete recovery within $8 \pm 2$ days while rest had hearing loss as an ongoing symptom.

ORL findings were confirmed by complete ear nose throat examination. On audiologic examination with a tuning fork at a frequency of $512 \mathrm{~Hz}$, the Weber test showed lateralization to the right in patients with left-sided hearing loss and to the left in those with right-sided hearing loss. Olfactory sensory loss was proved by UPSIT test and 4 basic taste modalities were tested using the appropriate solutions. Table 5 Denotes findings on ENT examination of patients.

\section{Discussion}

In December 2019, a novel coronavirus (CoV) epidemic, caused by the severe acute respiratory syndrome coronavirus-2 (SARS-CoV-2) emerged from China [7]. As the virus continues to be a global threat, scientists and researchers all across the world have accelerated their efforts to know more about the clinical presentation of COVID-19 in a bid to combat the disease more effectively [8]. As the main harboring site of the virus is the oropharyngeal and nasopharyngeal mucosa, widespread symptoms in relation to ear nose and throat persist [9]. While most of the present studies focus on presence of lower respiratory tract infections and other generalized symptoms like fever and myalgia, very little is known about the prevalence of ENT manifestations in Covid patients. ENTrelated symptoms of the patients were loss of smell $(53.5 \%)$, loss of sense of taste $(51.2 \%)$, hearing loss $(50.2 \%)$, sore throat $(47.1 \%)$, and tinnitus $(38.5 \%)$. With the spread of SARS-CoV-2 especially to European countries and the USA, the number of patients developing loss of sense of smell has been shown to increase. The American Ear Nose and Throat Academy stated that STL is one of the symptoms of COVID-19 disease, and the COVID-19 
Table 1 Frequency of generalized symptoms in COVID 19

\begin{tabular}{lll}
\hline Symptom & \% of patients & No. of patients \\
\hline Dry cough & 83.33 & 150 \\
Breathlessness & 90 & 162 \\
Fever & 95 & 171 \\
Fatigue & 93.33 & 168 \\
Diarrhea & 55.55 & 100 \\
\hline
\end{tabular}

Table 2 Onset and duration of generalized symptoms

\begin{tabular}{llll}
\hline Symptom & $\begin{array}{l}\text { (median) No. IQR } \\
\text { of days }\end{array}$ & $\begin{array}{l}\text { (median) Duration } \\
\text { before hosp referral }\end{array}$ \\
\hline Dry cough & 8 & $8.25-20.25$ & 3 \\
Breathlessness & 08 & $7.75-12.25$ & 1 \\
Fever & 08 & $6.75-15.25$ & 2 \\
Fatigue & 19 & $11.05-25.05$ & 4 \\
Diarrhea & 6 & $18.25-24.25$ & 2 \\
\hline
\end{tabular}

Table 3 Frequency of ENT related COVID 19 symptoms

\begin{tabular}{lll}
\hline Symptom & $\%$ of patients & No. of patients \\
\hline Throat pain & 47.22 & 85 \\
Rhinorrhea & 21.11 & 38 \\
Nasal blockage & 0 & \\
Sneezing & 0 & \\
Epistaxis & 0 & 68 \\
Headache & 37.77 & \\
Stridor & 0 & 100 \\
Hoarseness & 0 & 106 \\
Loss of smell & 55.5 & \\
Loss of taste & 58.88 & \\
Trismus & 0 & 98 \\
Earache & 0 & 120 \\
Ear discharge & 0 & \\
Hearing loss & 54.44 & \\
Tinnitus & 66.66 & \\
Aural fullness & 0 & \\
Facial weakness & 0 & \\
Dental pain & 0 & \\
Swelling in neck & 0 & \\
Others & $\mathrm{NA}$ & \\
\hline
\end{tabular}

disease screening test should be performed in patients with newly developed STL [10]. During the same period, Hopkins argued that there is strong evidence that SARSCoV-2 causes STL [11, 12]. Frequency of both generalised and specific ORL symptoms was significantly high in our study. Most patients although presented with cough, breathlessness and fever; patients gave history of ENT related symptoms $6.25 \pm 1.25$ days before the actual diagnosis of COVID 19 or hospital referral. While most patients reported complete recovery from ORL symptoms, hearing loss was seen to appear after the actual diagnosis.

The Fig. 1 denotes the presence of general symptoms in the entire sample size. Amongst which fever and cough were the most prominent symptoms followed by breathlessness and diarrhea.

The Fig. 2 denotes the presence of ORL symptoms in the entire sample size. Amongst which sore throat and hyposmia were the most prominent symptoms followed by loss of taste and hearing loss.

In our study, all the ENT symptoms identified were non specific in nature and did not involve any emergencies. No laryngeal involvement suggested by change in voice or hoarseness was documented. Similar results were stated earlier. As stated in other published articles, No reported sneezing, epistaxis, or post nasal discharge suggesting a meager role of nose in disease transmission, as compared to that of the throat $[4,13]$. The results of the current study resonate with other studies that fever (reported in $95 \%$ of the included patients), and cough (reported in $83.33 \%$ ) are the dominant symptoms of COVID-19 whereas gastrointestinal symptoms were less common, proposing the difference in viral predilection as compared with influenza, SARS-CoV, and MERS-CoV [14]. However, recent studies suggest multiple CNS involvement by the virus making ENT symptoms an integral part of the clinical presentation [15]. The most common ENT manifestations for COVID19 in the current study were loss of smell and taste sensation (26\%), sore throat (47.22\%), hearing loss (54.44\%) and headache $(37.77 \%)$, co relating with past studies showing similar results (31) However, it is clear that their incidence is much less than the incidence of fever and cough in COVID-19 patients (Fig. 3).

Kaye et al. report on 237 US patients with COVID-19 and found that $73 \%$ reported anosmia, and that loss of sense of smell was the initial symptom in $26.6 \%$ [16]. While Mao et al. found out anosmia in $5.1 \%$ of their studied cases several studies also recommend that presence of anosmia or hyposmia without nasal blockage or nasal congestion should be considered as a high index of suspicion for COVID-19 [10].

The pathogenesis of STL caused by SARS-CoV-2 virus is not yet clear. However, direct extension through the nasal mucosa via angiotensin-converting enzyme 2 receptor and extension to the olfactory bulb of SARS-CoV-2 are thought to be involved [17]. Despite all the unknown factors regarding the pathogenesis of STL caused by SARSCoV- 2, our study showed that SARS-CoV-2 can cause 
Table 4 Onset and denotes duration of ENT related symptoms

\begin{tabular}{|c|c|c|c|}
\hline Symptom & $\begin{array}{l}\text { (Median) No. } \\
\text { of days }\end{array}$ & IQR & $\begin{array}{l}\text { (median) Duration before } \\
\text { hosp referral }\end{array}$ \\
\hline $\begin{array}{l}\text { Throat pain } \\
\text { Rhinorrhea }\end{array}$ & 17 & $6.25-21.25$ & 7 \\
\hline $\begin{array}{l}\text { Nasal } \\
\text { blockage }\end{array}$ & 0 & & \\
\hline Sneezing & 0 & & \\
\hline Epistaxis & 0 & & \\
\hline Headache & 8.5 & $4.5-11.75$ & 6 \\
\hline Stridor & 0 & & \\
\hline $\begin{array}{l}\text { Loss of } \\
\text { smell }\end{array}$ & 20.5 & $12.75-22.5$ & 8 \\
\hline $\begin{array}{l}\text { Loss of } \\
\text { taste }\end{array}$ & 18 & $8.5-25.75$ & 5 \\
\hline Trismus & 0 & & \\
\hline Earache & 0 & & \\
\hline $\begin{array}{l}\text { Ear } \\
\quad \text { discharge }\end{array}$ & 0 & & \\
\hline $\begin{array}{l}\text { Hearing } \\
\text { loss }\end{array}$ & 13 & $9.5-16.75$ & 0 \\
\hline Tinnitus & 5 & $4-6$ & 0 \\
\hline $\begin{array}{l}\text { Aural } \\
\text { fullness }\end{array}$ & 0 & & \\
\hline $\begin{array}{l}\text { Facial } \\
\quad \text { weakness }\end{array}$ & 0 & & \\
\hline Dental pain & 0 & & \\
\hline $\begin{array}{l}\text { Swelling in } \\
\text { neck }\end{array}$ & 0 & & \\
\hline Others & NA & & \\
\hline
\end{tabular}

STL in infected patients, that STL may be the first and only symptom independent of other upper respiratory complaints in SARS-CoV-2-positive patients, and that majority of the patients developing STL due to SARS-CoV-2 show rapid improvement.

Auditory manifestation was not reported in the studies on COVID-19 and auditory complication due to coronavirus is little mentioned in the literature. In a previous report on other coronavirus infection, brainstem involvement was observed and the neuro auditory problem is a possible [18]. The study by Mustafa et al., stated that COVID-19 infection could have deleterious effects on cochlear hair cell functions despite being asymptomatic as reduction of high frequency pure-tone thresholds as well as the TEOAE amplitudes were detected. Likewise, a positive association with diagnosis of COVID 19 with the onset of sudden sensorineural hearing loss was noted in our study [18].
Table 5 Findings on ENT examination of patients

\begin{tabular}{llll}
\hline On examination & $\begin{array}{l}\text { Total } \\
\text { patients }\end{array}$ & $\begin{array}{l}\text { \% Patients of } \\
\mathrm{n}\end{array}$ & $\begin{array}{l}\% \text { Patients of } \\
\mathrm{N}\end{array}$ \\
\hline Pharyngitis & 52 & 61.17 & 28.88 \\
$\begin{array}{l}\text { Dehydrated oral } \\
\quad \text { mucosa }\end{array}$ & 33 & 38.82 & 18.33 \\
Hearing loss & 91 & 92.85 & 50.55 \\
Sinus tenderness & 0 & 0 & 0 \\
Loss of smell & 92 & 92 & 51.1 \\
Loss of taste & 95 & 89.6 & 51.35 \\
\hline
\end{tabular}

To further confirm the subjectively reported complaints of the patients, an ENT examination was performed that confirmed the data that was obtained after thorough history taking. 13 out of 18 patients complaining of sore throat had signs suggestive of either local pharyngeal inflammation or dryness without any evidence post nasal discharge. A substantial percentage of patients $(12 \%)$ were proven to have mild to moderate sensorineural hearing loss when subjected to tuning fork tests. On a careful otoscopic examination, none of the patients showed any major abnormalities in EAC or tympanic membrane. Absence of sinus tenderness on palpation and no signs of nasal discharge or congestion suggest no interplay of nasal cavity in the pathogenesis of the disease thus helping it differentiate from other maladies like acute rhinosinusitis or allergic rhinitis.

While several papers and research manuscripts mention about neuro invasive nature of the virus causing neuropathy in humans thus explaining extensive multi systemic involvement of the disease, it was impressive to note that a similar result was obtained in our study signifying a poly neuropathic damage caused by the virus resulting in varied manifestations and severe inflammatory response as seen in [19].

Since the study was conducted on admitted patients, each symptom was studied in detail with respect to its onset duration and progression. An average duration of symptoms and their onset before the actual diagnosis of the disease or admission to the hospital was plotted. As shown in Figs. 4 and 5.

While the major symptoms of fever, cough and breathlessness have a shorter duration before the actual diagnosis of the disease, ENT symptoms like sore throat, hearing loss and loss of smell and taste tend to show an earlier onset and a longer persistence.

In our population there was an alteration of the sense of taste, of the sense of smell, dryness of oral cavity and an auditory discomfort, symptoms probably linked to the neurotropism of the virus. Thus, anosmia, dysgeusia and xerostomia are early symptoms of COVID-19, which can 
Fig. 1 The presence of generalised symptoms in the entire sample size.
Fig. 2 The presence of ORL symptoms in the entire sample size

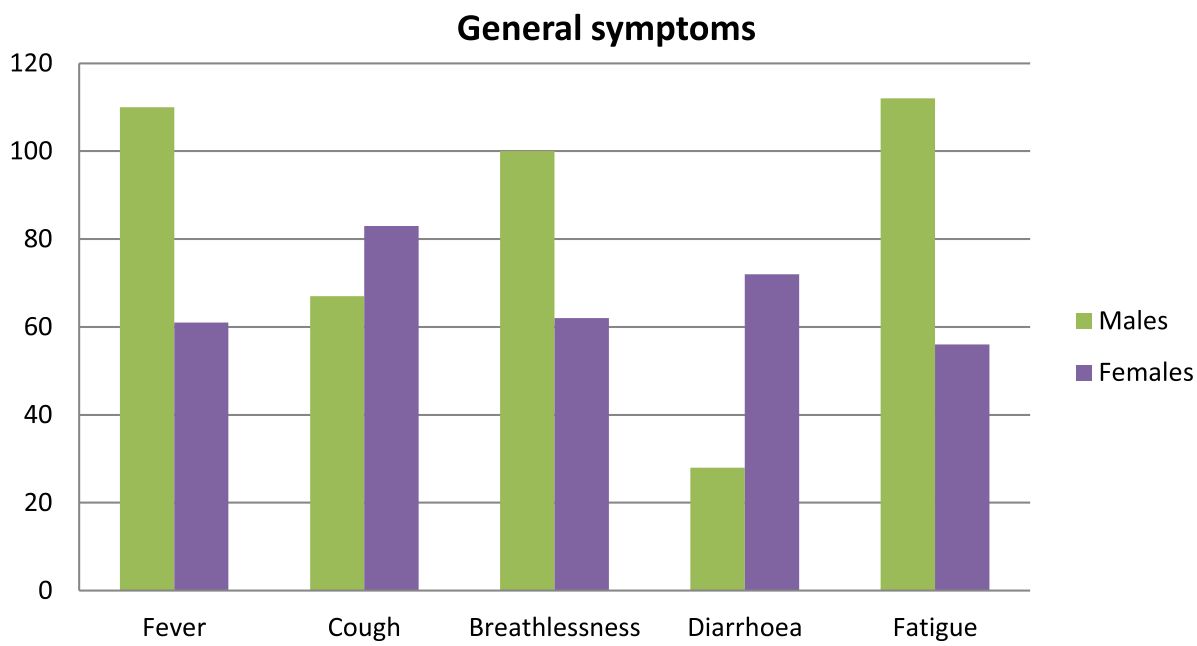

be exploited for an early quarantine and a limitation of viral contagion.

\section{Limitations}

Although the study was conducted with thorough research and knowledge of the subjects, there are few confounding factors and biases that add to the limitations of the study. As mentioned earlier, only the patients with mild to moderate symptoms were included in the study thus excluding the asymptomatic and patients with mild symptoms treated at home as also the patients falling under severe category and unable to provide thorough history. As seen in the demographic chart, maximum representation in the sample size was that of geriatric age group that might have been a confounding factor in the study. The symptoms were graded and answered on a subjective basis and no objective scales were used to confirm their presence. Study was solely based on patient's self report leaving room for recall bias. Ongoing symptoms present at the time of examination were not followed up later and progression of symptoms and their permanent sequelae if any were not studied. The study was purely non interventional and no endoscopic or radiological evidence was used to confirm symptoms. High reliability over RT-PCR analysis may have resulted in a contracted sample size due to inadequate specificity of the diagnostic test. Apart from lack of precise definition of disease, variations exist in clinical data collection and guidelines as the studies are rapidly being conducted on this advancing pandemic.

\section{Conclusion}

The rising number of cases of COVID 19 makes it mandatory for health care workers to have holistic knowledge about the disease and its presentation. A better understanding of the corona virus will not only aid in faster diagnosis and interpretation of symptoms earlier, but will 
Fig. 3 Comparison between ENT and non ENT symptoms

\section{Comparison between ENT and non ENT}

symptoms

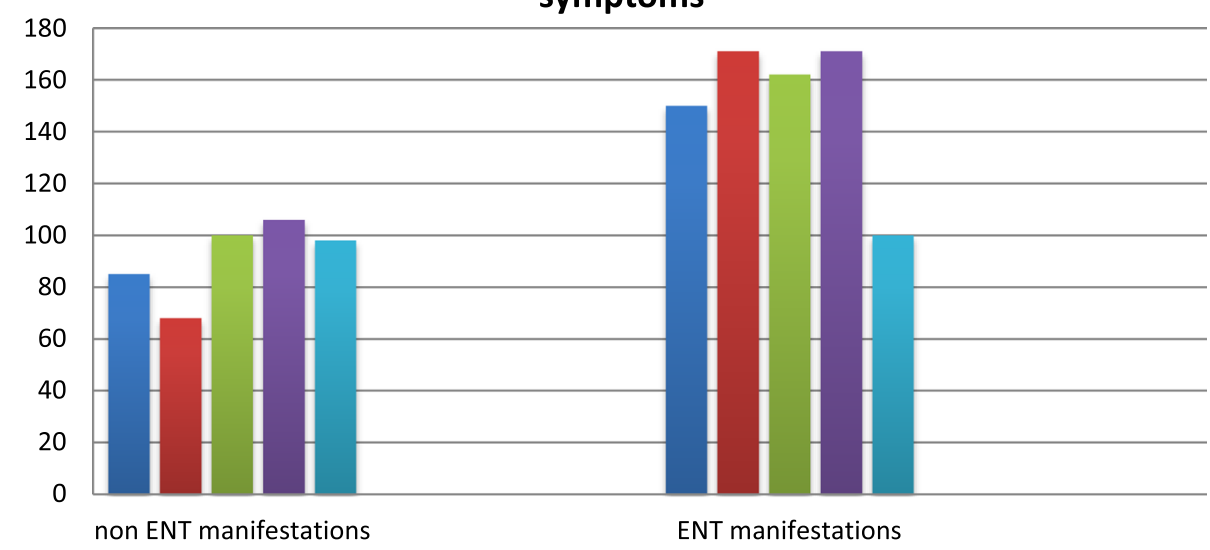

Fig. 4 Distribution of ORL symptoms

Fig. 5 Distribution of symptoms before and after diagnosis

\section{Distribution of ORL symptoms}

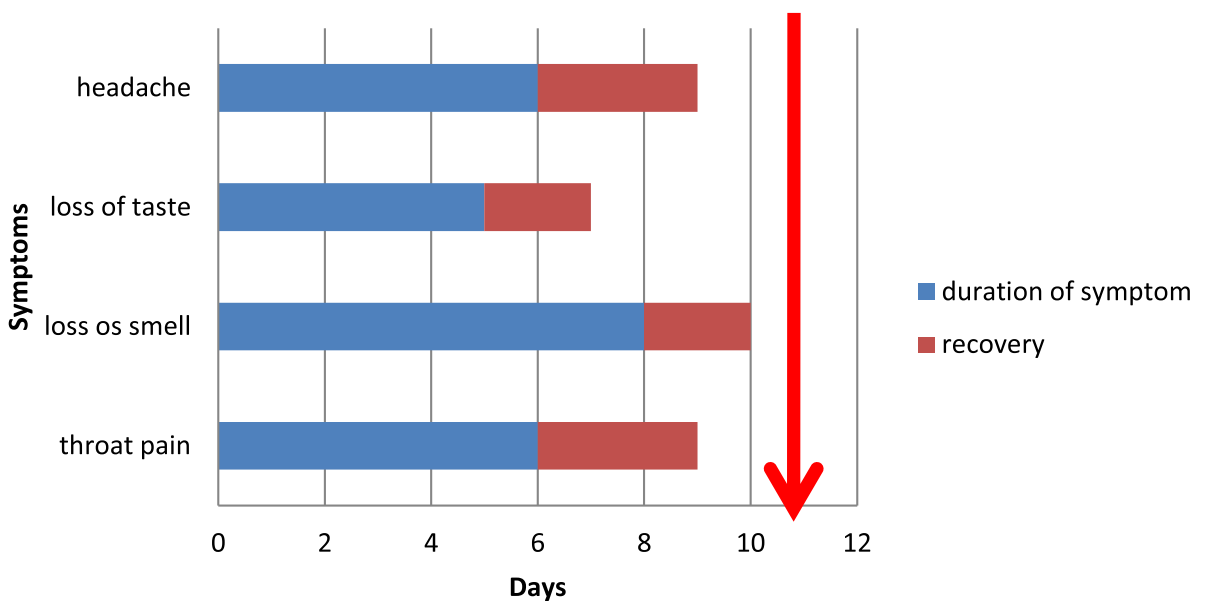

\section{Duration of symptoms}

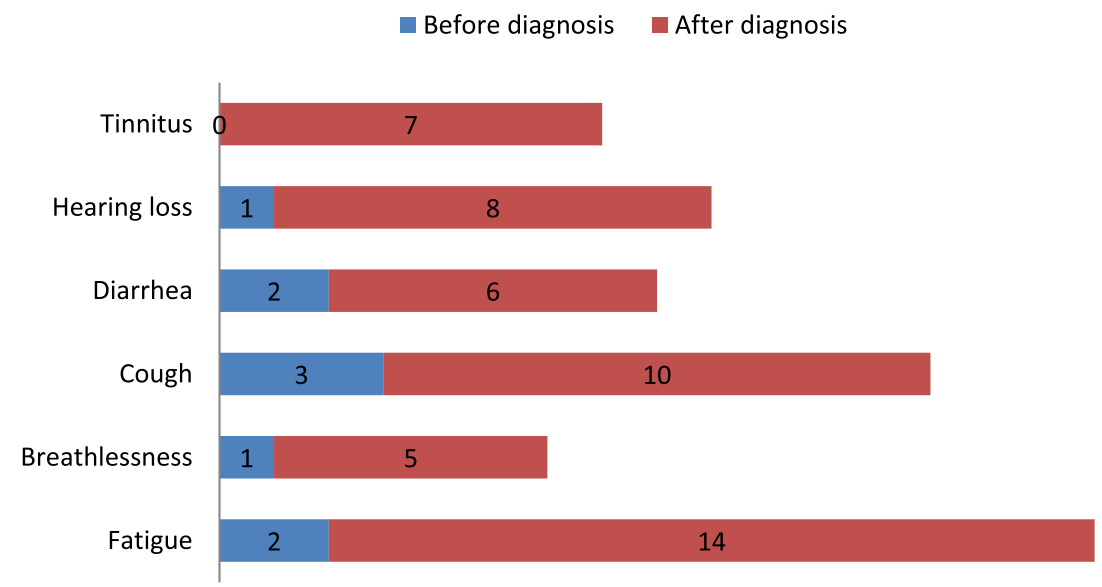


also merge helpful for designing better control measures. The results of this study show that in addition to lower respiratory symptoms, many COVID-19 patients also have Otorhinolaryngologic complaints. Although ORL related symptoms are not as common as fever, cough and breathlessness [14, 20], a mere absence of otolaryngological related symptoms shouldn't mean absence of disease as well. Relying solely on temperature and questioning the patient for cough or breathing difficulty may give a false sense of confidence.

A universal questionnaire comprising of ORL symptoms need to be made to make the diagnosis more complete and homogenous. Nevertheless, considering few latest researches regarding neurological and brain stem involvement in the disease pave way for a plethora of other symptoms that can be included the diagnostic criteria serving to make an accurate diagnosis and management protocols regarding isolation [16]. As the pandemic ensues, a thorough understanding of the virus and an emphasis on ORL related symptoms should add to the quality of care provided.

In our population there was an alteration of the sense of taste, of the sense of smell, dry eyes and of the oral cavity and an auditory discomfort, symptoms probably linked to the neurotropism of the virus. Furthermore, anosmia, dysgeusia and xerostomia are early symptoms of COVID-19, which can be exploited for an early quarantine and a limitation of viral contagion.

Acknowledgements The Authors express their thanks to patients for participation.

Funding No funding was received to conduct the above study.

\section{Compliance with Ethical Standards}

Conflicts of interest The authors declare no conflict of interest and do not have any potential financial conflict of interest related to or could influence this work.

Ethical Approval The research protocol was accented by the institution of ethics committee of the said institution and did not raise any ethics related concerns.

\section{References}

1. El-Anwar MW, Elzayat S, Fouad YA (2020) ENT manifestation in COVID-19 patients. Auris Nasus Larynx 47(4):559-564

2. Guan W, Ni Z, Hu Y, Liang W, Ou C, He J et al (2020) Clinical characteristics of coronavirus disease 2019 in China. N Engl J Med 382(18): 1708-1720

3. Drosten C, Günther S, Preiser W, Van der Werf S, Brodt HR, Becker $S$ et al (2003) Identification of a novel coronavirus in patients with severe acute respiratory syndrome. N Engl J Med 348(20):1967-1976
4. Huang C, Wang Y, Li X, Ren L, Zhao J, Hu Y et al (2020) Clinical features of patients infected with 2019 novel coronavirus in Wuhan, China. Lancet 395(10223):497-506

5. Avcı H, Karabulut B, Farasoglu A, Boldaz E, Evman M (2020) Relationship between anosmia and hospitalisation in patients with coronavirus disease 2019: an otolaryngological perspective. J Laryngol Otol 134(8):710-716

6. Lovato A, Rossettini G, Filippis C (2020) Sore throat in COVID19: comment on "Clinical characteristics of hospitalized patients with SARS-CoV-2 infection: a single arm meta-analysis." J Med Virol 92(7):714-715

7. Ashour HM, Elkhatib WF, Rahman MM, Elshabrawy HA (2020) Insights into the recent 2019 novel coronavirus (Sars-coV-2) in light of past human coronavirus outbreaks, vol 9, Pathogens. MDPI AG

8. Yin Y, Wunderink RG (2018) MERS, SARS and other coronaviruses as causes of pneumonia, 23 Respirology. Blackwell Publishing, Cambridge, pp 130-137

9. Salepci E, Turk B, Ozcan SN, Bektas ME, Aybal A, Dokmetas I et al (2020) Symptomatology of COVID-19 from the otorhinolaryngology perspective: a survey of 223 SARS-CoV-2 RNApositive patients. Eur Arch Oto-Rhino-Laryngol 13:1-11

10. Mao L, Jin H, Wang M, Hu Y, Chen S, He Q et al (2020) Neurologic manifestations of hospitalized patients with coronavirus disease 2019 in Wuhan China. JAMA Neurol. 77:683-690

11. Xydakis MS, Dehgani-Mobaraki P, Holbrook EH, Geisthoff UW, Bauer C, Hautefort C et al (2020) Smell and taste dysfunction in patients with COVID-19. Vol. 20. The Lancet Infectious Diseases. Lancet Publishing Group, New York, pp 1015-1016

12. Vaira LA, Hopkins C, Salzano G, Petrocelli M, Melis A, Cucurullo $\mathrm{M}$ et al (2020) Olfactory and gustatory function impairment in COVID -19 patients: Italian objective multicenter-study. Head Neck 42(7):1560-1569

13. Hajifathalian K, Mahadev S, Schwartz RE, Shah S, Sampath K, Schnoll-Sussman F et al (2020) SARS-COV-2 infection (coronavirus disease 2019) for the gastrointestinal consultant. World J Gastroenterol 26(14):1546-1553

14. Sun P, Qie S, Liu Z, Ren J, Li K, Xi J (2020) Clinical characteristics of hospitalized patients with SARS-CoV-2 infection: a single arm meta-analysis. J Med Virol 92(6):612-617

15. Mochan A, Modi G (2020) Neurological Involvement with COVID-19 Review. Wits J Clin Med 2(2):81

16. Moein ST, Hashemian SMR, Mansourafshar B, Khorram-Tousi A, Tabarsi P, Doty RL (2020) Smell dysfunction: a biomarker for COVID-19. Int Forum Allergy Rhinol 10(8):944-950

17. Mancini L, Quinzi V, Mummolo S, Marzo G, Marchetti E (2020) Angiotensin-converting enzyme 2 as a possible correlation between COVID-19 and periodontal disease. Appl Sci 10(18):6224

18. Mustafa MWM (2020) Audiological profile of asymptomatic Covid-19 PCR-positive cases. Am J Otolaryngol Head Neck Med Surg 41(3):102483. https://doi.org/10.1016/j.amjoto.2020.102483

19. Román GC, Spencer PS, Reis J, Buguet A, Faris MEA, Katrak SM et al (2020) The neurology of COVID-19 revisited: a proposal from the Environmental Neurology Specialty Group of the World Federation of Neurology to implement international neurological registries. J Neurol Sci 414:116884

20. Chen N, Zhou M, Dong X, Qu J, Gong F, Han Y et al (2020) Epidemiological and clinical characteristics of 99 cases of 2019 novel coronavirus pneumonia in Wuhan, China: a descriptive study. Lancet 395(10223):507-513

Publisher's Note Springer Nature remains neutral with regard to jurisdictional claims in published maps and institutional affiliations. 